\title{
Community awareness of which seizure type should present to healthcare providers; a potential risk factor of the epilepsy treatment gap
}

Ismat Babiker ( $\sim$ ismatbabiker94@gmail.com )

University of Medical Sciences and Technology

Mohamed K. Elnaeim

Alzaiem Alazhari University

Awab K.Elnaeim

University of Medical Sciences and Technology

\section{Research Article}

Keywords: knowledge, perception, types of epilepsy, seizure description, Sudan

Posted Date: October 19th, 2021

DOl: https://doi.org/10.21203/rs.3.rs-992880/v1

License: (c) (i) This work is licensed under a Creative Commons Attribution 4.0 International License.

Read Full License

Version of Record: A version of this preprint was published at Journal of the Neurological Sciences on October 1st, 2021. See the published version at https://doi.org/10.1016/j.jns.2021.119189. 


\section{Abstract}

Objective: the objective of this study was to assess the awareness of the community in Sudan of which seizure type(s) should present to health care providers.

Methods: This is a cross-sectional descriptive internet-based survey that was conducted in Sudan during the period from January to April 2018, using google forms. The survey consisted of demographic data (age, gender, educational level), a statement evaluating participants' sources of obtaining information regarding epilepsy, a statement assessing awareness about the primary care provider for people with epilepsy (PWE), and a statement describing the symptomatology of different seizure types in simple Arabic, asking what description(s) participants thought should present to health care providers. We included participants residing in Sudan, and those with a college degree or higher education. Four hundred sixty-seven participants completed the survey.

Results: 467 participants were included, of whom, 279 (60\%) were females. The mean age of participants was 28 years. Two-thirds of participants obtained their information from non-scientific sources. $84 \%$ of the participants were aware that doctors are the primary health care providers for people with epilepsy.

The majority (92.\%) of participants were aware that patients with symptoms corresponding to the generalized tonic-clonic seizure description should present to doctors, compared with two-thirds of participants for focal seizure symptom description, and only $30.6 \%$ of participants for absence seizure symptom description.

Conclusion: This study demonstrated poor awareness about the necessity of presentation for focal and absence seizures. We hypothesize that this lack of awareness may contribute to the epilepsy treatment gap, and we recommend further studies to examine this hypothesis.

\section{Highlights}

This article highlights a potential risk factor that may contribute to the epilepsy treatment gap.

\section{Background}

Epilepsy is the most common neurological disease that requires long-term healthcare, affecting almost 70 million patients worldwide (1), and affecting an additional 500 million as family members and caregivers (2). In developing countries, it is estimated that over $90 \%$ of people with epilepsy (PWE) do not receive appropriate treatment, a phenomenon known as the treatment gap (3) (4) (5).

Many causes and risk factors of the epilepsy treatment gap have been investigated in the literature. Those risk factors usually fall under two main categories: factors leading to deficits in health care provider seeking, or factors leading to lack of compliance once treatment has been initiated. 
We investigated two potential risk factors leading to deficits in health care provider seeking and consultation: (1) participants' awareness of whether doctors are the primary care providers for people with epilepsy, and (2) participants' awareness of different seizure presentations.

We hypothesize that even the educated community in Sudan lack awareness of different seizure types, and only consider that patients with generalized tonic-clonic seizures symptomatology should seek healthcare provider.

We conducted this study to assess the hypothesis that a disparity exists between community awareness of generalized tonic-clonic seizure symptoms, and symptoms corresponding to other seizure types. We chose to conduct this study among the educated community because, as people with lower education, levels are more likely to have poor awareness about epilepsy (6), including all seizure presentations, as well as many misbeliefs regarding epilepsy treatment.

\section{Methods}

\section{Study design and setting}

This cross-sectional descriptive study was conducted in Sudan during the period from January to April 2018 using an online survey that was distributed in social media groups that contain diverse groups of the Sudan population. We used Google Forms to collect data. Google form is a tool that allows data collection via a personalized survey. The information is collected and automatically connected to a spreadsheet from which it can be imported to analysis software programs. The post included a description of the study and the consent form and request to complete the survey. We did not collect any personal identifying information or email addresses and the participants were completely anonymous. This method was utilized to increase the number of study participants.

\section{Participants}

Our targeted population was the Sudanese population who reside in Sudan with a university degree or higher education. We excluded participants who are less than 18 years of age.

\section{Statistical Methods:}

We collected data from 467 participants, and then we analyzed the data using IBM SPSS statistics version 25 and used Pearson's Chi-square test, and t-test to test for possible associations between variables.

\section{Variables:}

The questionnaire consists of:

Age, Gender.

Statement evaluating participants' awareness of the primary care provider for people with epilepsy. 
One question evaluating participants' source(s) of obtaining information regarding epilepsy, and

One question describing the symptomatology of GTC, focal seizures, and absence seizures and asking participants which seizure description should present to the doctor.

\section{Results}

467 participants were included, of whom, $279(60 \%)$ were females. The mean age of participants was 28 years. Ages ranged between 18 and 73 , and the distribution curve was positively skewed Two-thirds of participants obtained their information from non-scientific sources. $84 \%$ of the participants were aware that doctors are the primary health care providers for people with epilepsy.

The majority of our participants (92\%) were aware that patients with the symptomatology of GTC seizures should present to the doctor, while only two-third reported that presentation of myoclonic seizures and focal seizures (68.5\%) (67\%) require healthcare provider evaluation. Only one third were aware that absence seizure symptomatology should present to the doctor(30.6\%).

\begin{tabular}{|ll|}
\hline & Number $(\mathbf{N = 4 6 7 )}$ \\
\hline Gender & \\
\hline Male & $188(40.3 \%)$ \\
\hline Age & $279(59.7 \%)$ \\
\hline Mean age & \\
\hline Standard deviation & 28.1 years \\
\hline Educational level & 8.435 years \\
\hline University & $357(76.4 \%)$ \\
\hline Higher education & $110(23.6 \%)$ \\
\hline Source of information & \\
\hline Scientific source(book, health care provider, education) & $284(60.9 \%)$ \\
\hline Nonscientific source(social media, people in community) & $289(61.9 \%)$ \\
\hline No source & $49(10.5 \%)$ \\
\hline
\end{tabular}

\section{Table (1)}

Demographical data of our participants 


\begin{tabular}{|c|c|}
\hline & Number $(N=467)$ \\
\hline \multicolumn{2}{|c|}{ Participants knowledge about the primary care provider for people with epilepsy } \\
\hline Doctors & $392(83.9 \%)$ \\
\hline Others & $75(16.1 \%)$ \\
\hline \multicolumn{2}{|c|}{ Participants' knowledge of which seizure description should present to a doctor } \\
\hline Generalized tonic-clonic epilepsy & $433(92.7 \%)$ \\
\hline Focal seizures with retained awareness & $313(67 \%)$ \\
\hline Myoclonic seizures & $320(68.5 \%)$ \\
\hline Absence seizures & $143(30.6 \%)$ \\
\hline
\end{tabular}

\section{Table (2)}

which seizure description should present to the doctor

\begin{tabular}{|lllll|}
\hline & Women & Men & $\begin{array}{l}\text { Higher } \\
\text { education }\end{array}$ & $\begin{array}{l}\text { University } \\
\text { education }\end{array}$ \\
\hline Absence & $32 \%$ & $28 \%$ & $34 \%$ & $29 \%$ \\
\hline Generalized tonic-clonic & $94 \%$ & $90 \%$ & $92 \%$ & $93 \%$ \\
\hline Myoclonus & $70 \%$ & $65 \%$ & $75 \%$ & $65 \%$ \\
\cline { 2 - 4 } & & & $\mathrm{P}<0.03$ & $64 \%$ \\
\hline $\begin{array}{l}\text { Focal seizures with retained } \\
\text { awareness }\end{array}$ & $68 \%$ & $63 \%$ & $70 \%$ & \\
\hline
\end{tabular}

\section{Table (3)}

Percentages of people who think that seizure descriptions should present to the doctor. The P-value for the chi-square test is provided for the significant association. 


\begin{tabular}{|c|c|c|c|c|}
\hline & Women & Men & Higher education & University education \\
\hline \multirow[t]{2}{*}{ During studies } & $32 \%$ & $16 \%$ & \multirow[t]{2}{*}{$22 \%$} & \multirow[t]{2}{*}{$27 \%$} \\
\hline & $P<0.00$ & & & \\
\hline \multirow[t]{2}{*}{ People in the community } & $40 \%$ & $55 \%$ & \multirow[t]{2}{*}{$45 \%$} & \multirow[t]{2}{*}{$47 \%$} \\
\hline & $P<0.00$ & & & \\
\hline \multirow[t]{2}{*}{ People in the medical field } & \multirow[t]{2}{*}{$24 \%$} & \multirow[t]{2}{*}{$21 \%$} & $32 \%$ & $20 \%$ \\
\hline & & & $P<0.01$ & \\
\hline Social media & $7 \%$ & $8 \%$ & $8 \%$ & $7 \%$ \\
\hline \multirow[t]{2}{*}{ Journal/book } & \multirow[t]{2}{*}{$12 \%$} & \multirow[t]{2}{*}{$13 \%$} & $18 \%$ & $11 \%$ \\
\hline & & & $P<0.04$ & \\
\hline \multirow[t]{2}{*}{ No source } & \multirow[t]{2}{*}{$7 \%$} & \multirow[t]{2}{*}{$12 \%$} & $5 \%$ & $11 \%$ \\
\hline & & & $P<0.02$ & \\
\hline
\end{tabular}

Table (4): Sources of knowledge chosen by participants. P values for the chi-square test are provided for significant associations.

Running t-test on the associations between the variables mentioned in table (5) revealed no statistically significant association. Note that Levene's test for the quality of variances was not significant for each of the associations measured; which reflects the validity of the t-test.

\section{Discussion}

This manuscript adds to the literature of epilepsy treatment gap in terms of highlighting a potential risk factor that may contribute to deficits in healthcare provider seeking behavior by assessing the participants' awareness of different seizures symptomatology and who should present to the doctor.

More than half of our participants reported at least one non-scientific source of knowledge about epilepsy; this is likely contributing to their lack of awareness of different seizure symptomatology.

Most of our participants (83.9\%) were aware that doctors are the primary care providers for PWE.

The majority of our participants $(92.7 \%)$ were aware of the need to seek a health care provider when asked about symptoms of generalized tonic-clonic seizures. Only two-thirds were aware of the need to present when asked about the description of focal seizures with retained awareness $(67 \%)$, focal seizures with impaired awareness (64.2\%), myoclonus (68.5\%), or temporal lobe epilepsy (64.2\%), compared to $30.6 \%$ who were aware of the need to present when suffering from symptoms of absence seizures. 
This may be explained by the that the community often perceives epilepsy as only a violent motor phenomenon, where the entire body jerks and patient loses consciousness, thus fail to address the need for doctor evaluation when part of the body jerks, or the patient just stares.

These results may signify an association between lack of awareness of different seizure presentations and epilepsy treatment gap, but further studies should be done to measure the statistical association between awareness about different seizure presentations and epilepsy treatment gap.

\section{Conclusion}

This study demonstrated poor awareness about the necessity of presenting to a healthcare provider when experiencing symptomatology of focal and absence seizures.

We hypothesize that this lack of awareness may contribute to the epilepsy treatment gap, and we recommend further studies to examine this hypothesis.

\section{Limitations}

As people with higher educational levels are expected to have better awareness about epilepsy, the deficiencies that we found might be more pronounced in the general population. Including only highly educated people in our study prevented analyzing the correlation between educational level and awareness about epilepsy.

\section{Declarations}

\section{Authors' contributions}

Ismat Babiker co-formed the study concept and design, co-developed the questionnaire, distributed the data collection sheet, and co-wrote all sections of the final manuscript.

Mohamed K. Elnaeim co-formed the study concept and design, co-developed the questionnaire, distributed the data collection sheet, and co-wrote all sections of the final manuscript.

Awab K. Elnaeim co-formed the study concept and design, co-developed the questionnaire, analyzed the data using IBM SPSS Statistics, distributed the data collection sheet, and co-wrote all sections of the final manuscript.

\section{Acknowledgments}

We are grateful to all our participants for their involvement in the study.

We thank Dr. Awab Hashim for assistance in the preparation of the manuscript and figures of the article.

\section{Ethical considerations}


The participants provided their written informed consent to participate in the study, the consent form was attached before the data collection sheet. There is no potentially identifiable human images or data is presented in the study.

\section{Conflict of interest}

All authors declare that there is no conflict of interest to be disclosed.

\section{Source of funding:}

None.

\section{References}

1. Ngugi AK, Bottomley C, Kleinschmidt I, Sander JW, Newton CR. Estimation of the burden of active and lifetime epilepsy: a meta-analytic approach. Epilepsia. 2010 May;51(5):883-90.

2. World Health Organization. WHO Framework Convention on Tobacco Control: Guidelines for Implementation: Article 5.3, Article 8, Article 11, Article 13. World Health Organization; 2010.

3. Shorvon SD, Farmer PJ. Epilepsy in developing countries: a review of epidemiological, sociocultural, and treatment aspects.

4. Epilepsia. 1988 Apr;29:S36-54.Diop AG, Hesdorffer DC, Logroscino G, Hauser WA. Epilepsy and mortality in Africa: a review of the literature. Epilepsia. 2005 Dec;46:33-5.

5. Scott RA, Lhatoo SD, Sander JW. The treatment of epilepsy in developing countries: where do we go from here?. Bulletin of the World Health Organization. 2001;79:344-51.

6. Daoud A, Al-Safi S, Otoom S, Wahba L, Alkofahi L. Public knowledge and attitudes towards epilepsy in Jordan. Seizure 2007;16(6):521-6. 